\title{
DILEMA ÉTICO NA ATUAÇÃO PROFISSIONAL: AMBIENTE EDUCACIONAL EM FOCO
}

\author{
Valquiria Correia Lourenço Doná ${ }^{1}$
}

\section{RESUMO}

Neste trabalho apresenta-se um relato sobre um dilema ético vivido pelo autor em seu ambiente laboral, bem como posicionamentos sobre critérios de avaliação da conduta humana, fundamentação dos dilemas éticos e morais e suas correlações elementais e uma possível "solução justa para o dilema ético". São relatos ancorados em autores consagrados no campo da filosofia, e com base nas vivências e saberes empíricos do autor. O escrito se divide em quatro etapas de forma clara e objetiva.

Palavras-chave: Dilemas Éticos. Ética Profissional. Conduta. Moral. Influência Cultural.

\section{ABSTRACT}

This paper presents an account of an ethical dilemma experienced by the author in his work environment, as well as positions on criteria for evaluating human conduct, justification of ethical and moral dilemmas and their elemental correlations and a possible "fair solution for the ethical dilemma". These are reports anchored in renowned authors in the field of philosophy, and based on the author's experiences and empirical knowledge. The writing is divided into four steps, in a clear and objective way.

Keywords: Ethical Dilemmas. Professional Ethics. Conduct. Morals. Cultural Influence.

\section{RESUMEN}

Este trabajo presenta un relato sobre un dilema ético experimentado por el autor en su ambiente de trabajo, así como posiciones sobre los criterios para evaluar la conducta humana, el fundamento de los dilemas éticos y morales y sus correlaciones elementales y una posible "solución justa al dilema ético". Son informes anclados en autores consagrados en el campo de la filosofía, y basados en las experiencias y conocimientos empíricos del autor. La escritura se divide en cuatro etapas, de forma clara y objetiva.

Palabras clave: Dilemas Éticos. Ética Profesional. Conducta. Moralidad. Influencia Cultural.

\footnotetext{
${ }^{1}$ Licenciada em Matemática (USP), Especialista em Fundamentos e Metodologias do Ensino da Matemática (Faisp). E-mail: valdona31@gmail.com
} 


\section{INTRODUÇÃO}

A ética é um dos objetos de estudo da Filosofia e trata de investigar um conjunto de princípios que direcionam e normatizam as ações humanas. Contudo, a ética não é sinônimo de moral, uma vez que não são valores extraídos dos costumes de uma comunidade específica, mas sim, das normas válidas e consagradas universalmente.

A disciplina de Filosofia tem seu espaço e importância no ambiente corporativo, por influenciar no zelo pela conduta, postura e pelo nome do profissional no mercado, por isso, visa levá-lo a atuar com cautela aos limites que sua profissão impõe, visando atingir o sucesso almejado no cargo.

Em se tratando dos dilemas éticos profissionais são muitas vezes traduzidos em decisões que os profissionais tomam baseadas em procedimentos e normas recomendadas e que, implicam em obediência a elas, evitando conflitos ou situações que podem levar esses profissionais a ser considerados como aéticos e sem conduta.

Winstanley e Woodall (2000) relatam que os atuais profissionais se mostram muito envolvidos na busca por melhores práticas para lidar com os problemas éticos, como códigos de conduta ou ouvidorias, por exemplo.

Manuel Velásquez (1998, p.51), salienta que uma pessoa absorve a prática ética quando está frente à determinada situação, onde busca e questiona os padrões morais absorvidos durante o desenvolvimento. É nesse momento que o indivíduo encontra argumentos que podem ir contra ou a favor dos padrões que ele mesmo acredita, testando a possibilidade de segui-los ou não. Já Aristóteles narra a moral como resultado prático do hábito:

A virtude moral é adquirida em resultado do hábito, donde ter-se formado o seu nome (ethiké) por uma pequena modificação na palavra ethos (hábito). Por tudo isso, evidencia-se que nenhuma das virtudes morais surge em nós por natureza (ARISTÓTELES, p. 39, 2001).

Segundo Mario Alencastro (1997, p.89), a ética profissional consiste em um conjunto de normas de conduta que devem ser sugeridas e executadas durante 12 o exercício profissional. As ações reguladoras da ética atingem o desempenho profissional, fazendo com que o profissional respeite à semelhança do próximo.

\section{CONMRRGÂNAASTEÓRCASDOMNDOCONIEMPORÂNEO}




\section{DESENVOLVIMENTO}

Inicia-se o escrito com uma proposta de analisar um dilema ético vivido no ambiente profissional, ancorado nas perguntas a seguir:

Imagine um dilema ético no ambiente de sua atuação profissional. Pense em algo que você pode vir a enfrentar, já enfrentou ou ainda está enfrentando; como agiria diante disso?

Sou professora e, como dilema ético em meio ao meu entorno laboral, vivo o impasse de notar que além dos problemas crônicos que enfrentamos com o modelo arcaico de ensino brasileiro, há uma tríade de forças que impedem que o processo de ensino e aprendizagem ocorra de forma satisfatória (aluno, escola, família), pois preferem o conforto de suas desobrigações, nesse sentido, o docente se vê num processo "Penélope", em que tece de dia e desfaz ao anoitecer (tenta fazer seu trabalho, mas é impedido, por ser obrigado a se ajustar ao sistema que lhe é imposto).

\section{Por que esse caso é considerado um dilema ético?}

Porque todos os envolvidos, família, escola, aluno e educador, sabem que não estão fazendo o seu melhor, mas deixam as coisas como estão para não saírem da zona de conforto que estão inseridos.

A escola não faz o seu papel de cobrar mais e como deveria, por medo de perder público, os pais afrouxam as rédeas para se isentarem da participação no processo de acompanhamento e apoio aos educandos.

O aluno não está interessado em usufruir do conhecimento, mas passar pelo processo da forma mais lúdica e leve possível, o educador por sua vez, atua de forma circense, tentando ser mais "boa gente" que bom formador.

Notamos assim que, as ações e costumes neste entorno, se adaptam a um tipo de comportamento que não é o correto aos olhos da lei ética, mas extremamente fiel aos preceitos que esse novo modelo de "ensinar e aprender" dita como moralmente correto.

Ainda que não tenha sido feita nenhuma citação literal, é notório que, entre as argumentações apresentadas, houve a fundamentação teórica, com base no material de estudo oferecido pela instituição e, que me levou a refletir sobre o assunto em questão, em especial, baseado na fala de Kant, que relatou que a nossa capacidade autônoma é fundamental para agirmos moralmente.

\section{CONERGÂNAASTEÓRCASDOMNDOCONIEMPORÂNEO}




\section{ANÁLISE DOS CRITÉRIOS DE AVALIAÇÃO DA CONDUTA HUMANA}

Como os valores culturalmente constituídos influenciam nossa compreensão sobre o que é justo?

A meu ver, a resposta à essa questão se deve ao fato de que para sermos "aceitos e bem-vistos" no meio em que vivemos, precisamos agir de forma que venha a respeitar as "normas e protocolos" do bem viver em coletivo, nesse sentido, somos moldados por esses protocolos que, regem toda a sociedade e que tem e prega a justiça como um atributo de moral e "valor-prestígio", para aqueles que agem de forma ética.

Percebe a repercussão de uma tomada de decisão no âmbito da cultura?

Sim, e as consequências, em geral, ocorrem de forma punitiva. É isso que ocorre quando tentamos agir ao nosso modo ou, de forma crítica aos padrões que fomos moldados.

Como identificar um problema ético no contexto social?

A ética atua em todos os princípios, valores e fatores que encaminham uma ação, estabelecendo nortes para o bem-estar coletivo ou individual e dessa forma, estabelece princípios gerais. Nesse sentido, uma ação imoral de alguém, faz com que um determinado grupo identifique sua imprudência "falta de ética".

Exatamente por isso, a ética pode, à medida que ganha importância dentro de uma sociedade, fazer-se de instrumento para a mudança da própria cultura, possibilitando assim, identificar um ou vários problemas.

FUNDAMENTOS TEÓRICOS CONDIZENTES COM A PROPOSTA DE ANÁLISE

Por que esse caso é considerado um dilema ético? Porque todos os envolvidos, família, escola, aluno e educador, sabem que não estão fazendo o seu melhor, mas deixam as coisas como estão, para não saírem da zona de conforto que estão inseridos.

\section{CONMRRGÁNAASTEÓRICASDOMNDOCONIEMPORÂNEO}




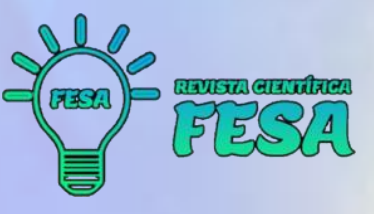

A escola não faz o seu papel de cobrar mais e como deveria, por medo de perder público, os pais afrouxam as rédeas para se isentarem da participação no processo de acompanhamento e apoio aos educandos. O aluno não está interessado em usufruir do conhecimento, mas passar pelo processo da forma mais lúdica e leve possível, o educador por sua vez, atua de forma circense, tentando ser mais "boa gente" que bom formador.

Notamos assim que as ações e costumes neste entorno, se adaptam a um tipo de comportamento que não é o correto aos olhos da lei ética, mas extremamente fiel aos preceitos que esse novo modelo de "ensinar e aprender" dita como moralmente correto.

Ainda que não tenha sido feita nenhuma citação literal, é notório que, entre as argumentações apresentadas, houve a fundamentação teórica, com base no material de estudo oferecido pela instituição e, que me levou a refletir sobre o assunto em questão, em especial, baseado na fala de Kant, que relatou que a nossa capacidade autônoma é fundamental para agirmos moralmente.

\section{FUNDAMENTAÇÃO DOS DILEMAS ÉTICOS E MORAIS E SUAS CORRELA- ÇÕES ELEMENTAIS}

Conforme estudamos, a ética e a moral são duas vertentes estudadas pela filosofia e estão intimamente ligadas. $O$ termo está presente em diferentes áreas, seja no trabalho, no convívio social ou no âmbito familiar. De forma geral, está relacionada ao modo como os costumes do que é certo ou errado ou do que é o bem e o mal são tratados. Assim sendo, a moral representa os hábitos e costumes individuais, bem como de uma sociedade ou de um local.

A ética é a área da filosofia que expressa, sem se ligar ao senso comum, o estudo da moral de forma imparcial, racional, laica e de forma organizada. Assim, é a ética que determina, por meio da razão, as condutas de certo ou errado.

Como bem destacou o professor Josimaber Rezende, a ética representa um conjunto de valores que regem nossa consciência, já a moral é a prática desses princípios e condutas.

A ética tem função preventiva para o bom convívio. Em se tratando dos dilemas éticos, estes ocorrem quando é necessário que tomemos decisões 


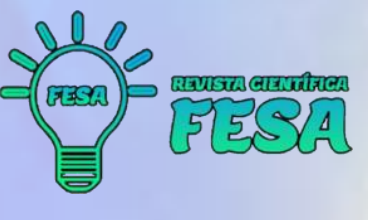

difíceis, levando em conta os valores morais, cujas consequências podem impactar na vida de terceiros. Por mais desafiador que pareça decidir como agir perante a esses dilemas, é fato que fazer a coisa certa é sempre o melhor caminho a ser seguido. Eles não podem ser resolvidos satisfatoriamente se a pessoa seguir um código moral tradicional.

Quando eles (dilemas) surgem, nem a sociedade nem os valores individuais podem fornecer uma resposta aceitável para o indivíduo que precisa tomar a decisão. Esses tipos de dilemas aparecem principalmente em disciplinas como filosofia, hipoteticamente. Seu principal objetivo é ajudar a pessoa solicitada a refletir sobre seus próprios valores, ética e código moral.

Quando surge um dilema ético, as duas opções possíveis contradizem, de alguma maneira, o sistema de valores da pessoa diante da situação ou as normas morais da sociedade ou cultura em que está imersa. De qualquer forma, escolher entre as duas opções é muito difícil.

Existem vários tipos de dilemas tais como: Dilemas hipotéticos: são aqueles em que a pessoa se depara com uma situação que dificilmente será enfrentada na vida real. A maioria dos utilizados em um contexto educacional pertence a esta categoria.

Dilemas reais: De muitas maneiras, os dilemas reais são o oposto dos hipotéticos.

São situações reais nas quais a pessoa precisa tomar uma decisão complicada ou um exemplo educacional que tem uma relação muito mais próxima com a vida do próprio aluno.

Dilemas abertos: Quando surge um dilema aberto, os alunos recebem todas as informações necessárias sobre uma situação; no entanto, eles não são explicados como a história é resolvida. Seu objetivo é incentivar os alunos a discutir o curso de ação que deve ser seguido pelo protagonista da ação.

Dilemas fechados: Nos quais os alunos são informados não apenas sobre qual é a situação, mas também sobre a decisão tomada pelo protagonista da história. O objetivo dos alunos, portanto, é discutir entre si se a pessoa fez a coisa certa ou não e por quê.

Dilemas completos: Quando um dilema ético completo é apresentado, todos os detalhes da situação analisada são compartilhados com os alunos. Dessa 
forma, os participantes conhecem perfeitamente as consequências de cada uma das opções possíveis. Etc...

\section{MODELOS ÉTICOS ABORDADOS}

Ética da Virtude - Aristóteles (Para Aristóteles, a virtude pode e deve ser adquirida e desenvolvida pelo exercício. Podemos, então, cultivar a virtude através de nossa autonomia racional de escolher o que fazer e do hábito de praticar boas ações. A virtude, assim, está ligada ao hábito de praticar boas ações, mas Aristóteles enfatiza que a virtude é consequência de nossa disposição, de nossa escolha racional, de nossa autonomia para praticar estas boas ações. A virtude, para Aristóteles, é a consequência de nossa escolha deliberada, de nossa disposição em equilibrar duas ações extremas, dois vícios.)

Ética do Dever- Kant (Para Kant, a moralidade vigente não deve impor ao indivíduo o que ele deve fazer, e sim o indivíduo deve impor a si mesmo uma moral. Assim, a ética de Kant prima pela autonomia, pois valoriza o indivíduo enquanto legislador de sua própria moral e não a moralidade que nos é exterior.)

Ética Utilitarista - John S. M e Jeremy B (O autor defende que toda ação moral deve visar à utilidade em vista da realização da felicidade. A felicidade, por sua vez, é o maior bem que podemos almejar e está ligada fundamentalmente à ausência de dor e presença de prazer, mas não apenas isso, pois, para sermos felizes, também necessitamos cultivar a virtude e aprimorar o caráter. Assim, toda ação moral deve considerar o critério da utilidade com vistas à realização da nossa felicidade.)

Ética da Responsabilidade - Hans Jonas (O autor apresenta a responsabilidade enquanto princípio importante para fundamentar a ética de uma civilização em que a tecnologia ofertou poderes de imensurável utilização, que, da mesma forma, produzem imprevisíveis consequências éticas, catastróficas para a humanidade.) 


\section{ANÁLISE DO VÍDEO DILEMA ÉTICOS}

Com base nos textos lidos e vídeo assistido, foram apontados diversos dilemas, tais como: o relato da obra: "A escolha de Sofia", que aborda situações nas quais nenhuma opção é satisfatória.

Dilema sobre a capacidade das UTIS em lidarem com a demanda de pessoas doentes, frente aos recursos e condições para salvá-las.

Dilema individual e coletivo (Sobre minha atuação em meio à propagação da doença).

Dilema economia $x$ vidas (paramos a economia para salvar vidas ou deixamos a roda da fortuna girar e que morram algumas pessoas para trabalhar no "movimento dessa roda").

Dilema dos invisíveis da pandemia (Pessoas que por estarem à margem da sociedade, emergiram aos olhos do mundo, como os maiores miseráveis e que vivem com migalhas).

Dilemas sobre o acesso a educação digital (Mostrando quem são os mais carentes dos recursos tecnológicos do país).

Como foi possível notar, a vida real também se mostra cheia de decisões desafiadoras que precisam ser tomadas no decorrer da existência. Nesse sentido, é importante que os indivíduos tenham sempre certeza a respeito de seus valores morais, para que consigam tomar decisões de forma tranquila e consciente em relação ao que acreditam.

\section{POSSÍVEL SOLUÇÃO "JUSTA" AO DILEMA ÉTICO: QUAL SERIA A SOLU- ÇÃO MAIS ADEQUADA DO PONTO DE VISTA ÉTICO?}

Conforme estudado, o ser humano vive diversos dilemas éticos e morais, em todos os âmbitos de relação e atuação humana, por isso, precisamos ter cautela e criticidade para lidar com cada um deles.

No que tange ao enfrentamento de dilemas éticos no âmbito laboral, creio que todos nós já enfrentamos situações como essa, por exemplo: denunciar ou não um ato antiético cometido por um colega de trabalho. 


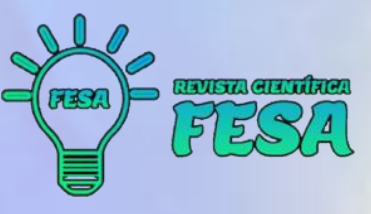

Situações como essas acabam nos levando a tomar uma atitude reacional ou emocional, tendendo a revelar o ocorrido e aceitar a punição do colega ou, imaginar que isso não voltará ocorrer, caso converse sobre esse fato com a pessoa que, poderá refletir sobre sua conduta. Porém, a meu ver, em um momento como esse, o ideal é pensar se nós, enquanto profissionais da mesma empresa e pessoa, se não estaríamos "compactuando" com a ideia e pensamento do colega que cometeu o ato antiético. Por isso, talvez o ideal seria conversar com esse colega e mostrar que reprovamos sua postura e que ele precisa refletir sobre esse feito. Essa atitude, para mim, vai de encontro ao modelo ético da virtude (Aristóteles), que afirma que a virtude pode e deve ser adquirida e desenvolvida pelo exercício, por estar ligada ao hábito de praticar boas ações, uma vez que, a virtude, para ele, é a consequência de nossa escolha deliberada, de nossa disposição em equilibrar duas ações extremas, dois vícios.

Considerando a atuação profissional sob o norte da ética, penso que o indivíduo que tem ética profissional cumpre com todas as atividades de sua profissão, seguindo os princípios determinados pela sociedade e pelo seu grupo de trabalho. E como nos é sabido, cada profissão tem o seu próprio código de ética, que pode variar ligeiramente, graças a diferentes áreas de atuação, no entanto, há elementos da ética profissional que são universais e por isso, aplicáveis a qualquer atividade profissional, como a honestidade, responsabilidade, competência etc.

\section{CONSIDERAÇÕES FINAIS}

Neste escrito foram apresentadas de forma condensada, visões sobre diversos dilemas éticos, bem como discorreu-se sobre modelos éticos, abordados com base nos autores e suas posições tais como: Ética da Virtude (Aristóteles), Ética do Dever (Kant, Ética Utilitarista - John S. M e Jeremy B) e Ética da Responsabilidade (Hans Jonas).

Como visto, a ética é uma ampliação do estudo filosófico que discute sobre a conduta do homem, e sua relação com um determinado grupo social e nos mais diversos ambientes de atuação.

Essas reflexões servem para esclarecer quais ações profissionais são passivas de serem postas em prática na comunidade e âmbito profissional, 
uma vez que pensar na ética no entono laboral pode contribuir para que as ações práticas possam ser consideradas justas, positivas e morais no espaço corporativo.

\section{REFERÊNCIAS BIBLIOGRÁFICAS}

ARISTÓTELES. Ética a Nicômaco. Tradução: Mário da Gama Kuriy. 4. ed. Brasília: Editora Universidade de Brasília, 2001.

GHILLYER, A. W. Ética nos negócios. 4. ed. Porto Alegre: AMGH, 2015.

KANT, Immanuel. Fundamentação da Metafísica dos Costumes e Outros Escritos. São Paulo: Martin Claret: 2004.

NASCIMENTO, L. Por que as escolhas difíceis podem ajudar você a pensar [decidir] melhor? Afinal, o que é um dilema? Discursividade. 2016. Disponível em: http://discursividade.com.br/tag/bonde-desgovernado/.

PACHECO, L. K.; NESI, M. J. A ética de Aristóteles, de Kant e de Mill. In: Filosofia: livro didático. 4. ed. Palhoça: UnisulVirtual, 2011. p. 175-196. Disponível em:http://joinville.ifsc.edu.br/ sergio.sell/m\%C3\%B3dulo\%206/\%C3\%A9tica\%20de\%20Arist\%C3\%B3teles_Kant_e_Mill.pdf.

PORFÍRIO, F. "Ética"; Brasil Escola. Disponível em: https://brasilescola.uol.com.br/sociologia/o-que-etica.htm. Acesso em 05 de setembro de 2020.

VELÁSQUEZ, M. G. Business ethics: concepts and cases. 4. ed. Upper Saddle River, NJ: Prentice Hall, 1998.

WINSTANLEY, D., \& WOODALL, J. The ethical dimensions of human resource management. Human Resource Management Journal, (2000). Disponível em: HTTP://DX.DOI.ORG/10.1111/J.1748-8583.2000.TB00017. Acesso: $15 / 07 / 2021$ 